\title{
Effect of the amount of Autologous Hematopoietic Stem Cells on Survival and Engraftment in Multiple Myeloma
}

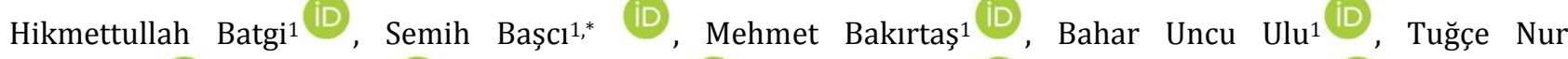 \\ Yiğenoğlu$^{1}(\mathbb{D})$, Jale Yıldız ${ }^{(i D}$, Dicle İskender ${ }^{1}$ (D) , Nurgül Özcan ${ }^{2}$, Mehmet Sinan $\operatorname{Dal}^{1}$ (D), Merih Kızıl \\ Çakar ${ }^{1}$ and Fevzi Altuntaş ${ }^{1}$ \\ 1 Department of Hematology and Bone Marrow Transplantation Center, Dr. Abdurrahman Yurtaslan Oncology Training and Research Hos pital, University of \\ Health Sciences, Ankara, Turkey \\ 2 Department of Biochemistry, Dr. Abdurrahman Yurtaslan Oncology Training and Research Hospital, University of Health Sciences, Ankara, Turkey
}

* Corresponding author: Semih Bașc1, Department of Hematology and Bone Marrow Transplantation Center, Dr. Abdurrahman Yurtaslan Oncology Training and Research Hospital, University of Health Sciences, Ankara, Turkey. Tel: +90 312 3360909-7215; Email: dr.semihbasci@gmail.com

Received 2021 February 02; Revised 2021 February 28; Accepted 2021 April 20.

\begin{abstract}
Background: Autologous stem cell transplantation (ASCT) is currently a gold standard treatment for eligible multiple myeloma (MM) patients. The recommended dose of CD34+ hematopoietic progenitor cells (HPCs) for adequate engraftment is above $2 \times 10^{6}$ cells $/ \mathrm{kg}$. Objectives: This study aimed to evaluate the relationship between the number of CD34+ HPCs and the survival in MM patients who underwent ASCT in the Hematology Department of Abdurrahman Yurtaslan Ankara Oncology Training and Research Hospital, Ankara, Turkey.

Methods: The statistical population of this consisted of 200 MM patients who underwent ASCT within 2009-2019. The clinical characteristics of the patients, disease status pre-SCT, number of infused CD34+ cells, neutrophil, and platelet engraftment days were recorded. The patients were divided into two groups, based on whether the re-infused CD34+ HPCs dose was $<5 \times 10^{6}$ cells $/ \mathrm{kg}$ (Group 1) or $\geq 5 \times 10^{6}$ cells $/ \mathrm{kg}$ (Group 2). The groups were compared in terms of engraftment and overall survival (OS) times.

Results: A total of 200 patients were included in our study. Group 1 ( $\mathrm{n}=125)$ included patients with $<5 \times 10^{6}$ cells $/ \mathrm{kg}$ CD34+ $\mathrm{HPC}^{\mathrm{re}}-$ infusion, and Group $2(\mathrm{n}=75)$ consisted of patients with $\geq 5 \times 10^{6} \mathrm{cells} / \mathrm{kg}$ CD34+ $\mathrm{HPC}$ re-infusion. The patients' median age scores in Group 1 and Group 2 were 57 (25-71) and 56 (33-72) years, respectively. The median follow-up period was 33 months (6-130). The median OS of all patients was 71 months (95\% confidence interval, 59.1-82.9). The median neutrophil and platelet engraftment times were similar between the groups $(\mathrm{P}=0.4$ and $\mathrm{P}=0.4$, respectively). In both groups, the median OS time was 71 months $(\mathrm{P}=0.8)$, which was similar. Conclusion: The greater number of CD34+ HPCs re-infusion for ASCT after high dose melphalan chemotherapy in MM patients did not affect platelet and neutrophil engraftment time and OS; therefore, this amount of reinfusion was not required.

Keywords: CD34+ hematopoietic progenitor cells, Engraftment, Multiple myeloma, Survival
\end{abstract}

\section{Background}

Multiple myeloma (MM) constitutes about 10\% of hematologic malignancies and approximately $1 \%$ of all malignancies (1). High-dose melphalan and autologous stem cell transplantation (ASCT) is the standard treatment strategy in MM for eligible patients (2).

The number of $\mathrm{CD}_{34}{ }^{+}$hematopoietic progenitor cells (HPCs) that can be mobilized in ASCT depends on various factors, including the underlying disease, such as MM, non-Hodgkin lymphoma, and Hodgkin lymphoma (3). The generally accepted minimum number of CD34+ cells for promoting ASCT in MM is $2 \times 10^{6}$ cells $/ \mathrm{kg}(3)$. The results of studies show that the administration of $<5 \times 10^{6}$ cells $/ \mathrm{kg}$ of $\mathrm{CD} 34^{+}$ HPCs prolongs engraftment time and mainly affects platelet recovery in an adverse way (4-6). However, higher yields of $5 \times 10^{6} \mathrm{CD} 34^{+}$cells $/ \mathrm{kg}$ are aimed at many centers since they are associated with faster neutrophil and platelet recovery, also reducing hospitalization, and even influencing survival (4-7). The relationship of the number of $\mathrm{CD}_{3} 4^{+}$HPCs administered in the first stem cell transplant with neutrophil, platelet engraftment, and survival was controversial in the literature (4-6). As a result, stem cell mobilization and ASCT are considered complex processes involving many procedures and treatment applications. For this reason, our study carries the advantage of a unicenter study with the established staff and a standard conditioning regimen (i.e., melphalan) and standard operating procedures.

\section{Objectives}

This study aimed to evaluate the relationship of the number of $\mathrm{CD}_{3} 4^{+} \mathrm{HPCs}$ with the duration of engraftment and survival in patients with MM who underwent ASCT at the Hematology Department of 
Abdurrahman Yurtaslan Ankara Oncology Training and Research Hospital, Ankara, Turkey.

\section{Methods}

\subsection{Patients}

This study included $200 \mathrm{MM}$ patients who underwent ASCT at the Hematology Department of Abdurrahman Yurtaslan Ankara Oncology Training and Research Hospital between 2009 and 2019. Only patients with a single ASCT were included in the study. Patients with double ASCT and allogeneic stem cell transplants were excluded from the research.

All patients received median 4 cycles (range: 212) of bortezomib and dexamethasone; bortezomib, cyclophosphamide, dexamethasone; bortezomib, dexamethasone, and thalidomide; bortezomib, dexamethasone, thalidomide, cisplatin, doxorubicin, cyclophosphamide, and etoposide; bortezomib, lenalidomide, and dexamethasone; bortezomib, lenalidomide, dexamethasone, cisplatin, doxorubicin, cyclophosphamide, and etoposide; bortezomib, melphalan, and prednisone; lenalidomide plus lowdose dexamethasone or vincristine, doxorubicin, dexamethasone chemotherapy during the prebortezomib era, 28-day schedules for induction chemotherapy for MM. The patients were divided into two groups according to the given number of CD34+ HPCs. Group $1(n=125)$ and Group $2(n=75)$ consisted of patients with the re-infusions of $\mathrm{CD}^{+} 4^{+}$ $\mathrm{HPC}$ of $<5 \times 10^{6}$ cells $/ \mathrm{kg}$ and $\mathrm{CD} 34^{+} \mathrm{HPC} \geq 5 \times 10^{6}$ cells $/ \mathrm{kg}$, respectively. All the data were analyzed retrospectively.

As a standard of care/action of the hospital of Abdurrahman Yurtaslan Ankara Oncology Training and Research, all ethical considerations were strictly followed, and all of the patients gave their informed consent for the procedure at the time of hospitalization and before the administration of chemotherapy and other relevant diagnostic/ therapeutic procedures under the Declaration of Helsinki (ethical approval number: 2020-10/852).

\subsection{Stem Cell Mobilization}

During stem cell mobilization for ASCT, stem cells were collected from 157 patients only by granulocyte colony-stimulating factor (G-CSF). Biosimilars equivalent to G-CSF, especially filgrastim or lenograstim, were also used, and $2 \times$ $5 \mathrm{mcg} / \mathrm{kg}$ G-CSF was given subcutaneously for at least 4 days.

Other patients were collected with cyclophosphamide + G-CSF $(n=31)$ and plerixafor + $\mathrm{G}-\mathrm{CSF}(\mathrm{n}=12)$ due to mobilization failure with G-CSF alone.

\subsection{Response}

The neutrophil engraftment time was accepted as the first day of 3 consecutive days with an observed absolute neutrophil count of $\geq 0.5 \times 10^{9}$ /L. The platelet engraftment time was regarded as the first day of 3 consecutive days with platelet count measured at the value of $\geq 20 \times 10^{9} / \mathrm{L}$ without the need for transfusion.

\subsection{Endpoints}

The primary aim of this study was to demonstrate the relationship of the amount of $\mathrm{CD}^{2}{ }^{+}$HPCs with the duration of platelet and neutrophil engraftment. The secondary endpoint was to investigate the effect of the infused CD34+ HPCs count at the $5 \times 10^{6}$ cells $/ \mathrm{kg}$ cut-off value on the long-term overall survival (OS).

\subsection{Statistics}

The collected data were analyzed in IBM SPSS Statistics for Windows (Version 26.0. Armonk). Descriptive statistics were utilized to display patient and disease characteristics. Continuous variables were presented as median (minimummaximum) and categorical variables were presented as numbers and percentages. The continuous variables were tested for normality using a histogram and Kolmogorov-Smirnov test. The Chi-square and Mann-Whitney $U$ tests were used for categorical variables and non-parametric continuous variables, respectively, for comparisons among the groups. Spearman test was performed to assess if any significant correlation existed between $\mathrm{CD} 4^{+}$and engraftment times. Kaplan-Meier survival analyses were conducted to estimate OS. Log-rank test was utilized to evaluate the effects of the number of CD34+ HPCs groups on OS. The pvalue of $\leq 0.05$ was regarded as statistically significant.

\section{Results}

\subsection{Patients' Characteristics}

A total of 200 patients were included in our study, divided into Group $1(\mathrm{n}=125)$ and Group 2 $(n=75)$. The median infused number of CD34+HPCs was obtained at $4.62 \times 10^{6}$ cells $/ \mathrm{kg}\left(2.3-9.3 \times 10^{6}\right.$ cells $/ \mathrm{kg}$ ). The median age of the included patients was estimated at 57 (25-72) years, with the median age scores of 57 (25-71) and 56 (33-72) years for patients in Group 1 and Group 2, respectively. The clinical baseline characteristics of both groups are presented in Table 1.

\subsection{Hematologic Recovery}

The median scores of platelet and neutrophil engraftment time were calculated at 12 days (7-24) and 11 days (9-21) for the whole patients, respectively. Engraftment failure was not observed in the cohort. The median scores of neutrophil 


\begin{tabular}{|c|c|c|c|}
\hline Factors & CD $34<5 \times 10^{6}(n=125)$ & CD $34 \geq 5 \times 10^{6}(n=75)$ & P-value \\
\hline Age & $57(25-71)$ & $56(33-72)$ & 0.9 \\
\hline Gender (M/F) & $72 / 53$ & $46 / 29$ & 0.6 \\
\hline MM subtype & & & 0.8 \\
\hline IgG kappa & $40(32 \%)$ & $29(38.7 \%)$ & \\
\hline IgG lambda & $24(19.2 \%)$ & $16(21.3 \%)$ & \\
\hline IgA kappa & $19(15.2 \%)$ & $6(8 \%)$ & \\
\hline IgA lambda & $11(8.8 \%)$ & $6(8 \%)$ & \\
\hline IgD kappa & $1(0.8 \%)$ & $1(1.3 \%)$ & \\
\hline IgD lambda & $1(0.8 \%)$ & $1(1.3 \%)$ & \\
\hline Kappa light chain & 17 (13.6\%) & $12(16 \%)$ & \\
\hline Lambda light chain & $12(9.6 \%)$ & $4(5.3 \%)$ & \\
\hline Pre-transplant response & & & 0.6 \\
\hline $\mathrm{CR}$ & $43(34.7 \%)$ & $30(40 \%)$ & \\
\hline VGPR & $39(31.5 \%)$ & $19(25.3 \%)$ & \\
\hline PR & $30(24.2 \%)$ & $22(29.3 \%)$ & \\
\hline Stable disease & $9(7.3 \%)$ & $3(4 \%)$ & \\
\hline Refractory & $3(2.4 \%)$ & $1(1.3 \%)$ & \\
\hline $\mathrm{N} / \mathrm{A}$ & 1 & & \\
\hline Post-transplant response & & & 0.3 \\
\hline $\mathrm{CR}$ & 67 (77.9\%) & $52(82.5 \%)$ & \\
\hline VGPR & $8(9.3 \%)$ & $4(6.3 \%)$ & \\
\hline PR & $6(7 \%)$ & 7 (11.1\%) & \\
\hline Stable disease & $2(2.3 \%)$ & 0 & \\
\hline Refractory & $3(3.5 \%)$ & 0 & \\
\hline N/A & 39 & 12 & \\
\hline Radiotherapy & $16(14 \%)$ & $8(10.8 \%)$ & 0.5 \\
\hline Chemotherapy cycle $(\geq 2)$ & $74(60.2 \%)$ & $49(65.3 \%)$ & 0.5 \\
\hline
\end{tabular}

engraftment time were 11 days (9-19) and 11 days (9-21) in Group 1 and Group 2, respectively; therefore, no statistically significant differences were obtained $(\mathrm{P}=0.4)$.

Furthermore, median scores of platelet engraftment time were similar in Group 1 and Group 2 (12 (7-23) days and 12 (9-24) days, respectively; $\mathrm{P}=0.4$ ) (Table 2 ). The analysis of $\mathrm{CD}^{2} 4^{+}$cell count was conducted for the correlation with neutrophil and platelet engraftment times; however, no significant correlation was observed (0.07 and 0.75 , respectively).

\subsection{Overall Survival}

The median follow-up period of the patients was 33 months (6-130). During follow-up, 33 (23\%) and $30(40 \%)$ patients in Group 1 and Group 2, respectively, passed away. The mortality rate related to the 100-day transplantation was obtained at $2 \%$ (4 patients passed away). The median OS for all patients was estimated at 71 months $(95 \%$ confidence interval [CI], 59.1-82.9). The median scores of OS were 71 (63.6-78.4) months and 71 (38.9-103.1) months for patients in Group 1 and Group 2, respectively ( $\mathrm{P}=0.8)$ (Table 3 and Figure 1 ).

\begin{tabular}{|c|c|c|c|c|}
\hline & $\begin{array}{c}\mathrm{CD} \mathrm{34}^{+}<5 \times 10^{6} \text { cell } / \mathrm{kg} \\
(\mathrm{n}=125)\end{array}$ & $\begin{array}{c}\text { CD34 }^{+} \geq 5 \times 10^{6} \text { cell } / \mathrm{kg} \\
(n=75)\end{array}$ & $\mathrm{CD} 4^{+}$cell/kg & P-value \\
\hline Neutrophil engraftment time (days) & $11(9-19)$ & $11(9-21)$ & $\mathrm{r}=0.162$ & $0.4 ; 0.07$ \\
\hline Platelet engraftment time (days) & $12(7-23)$ & $12(9-24)$ & $r=0.03$ & $0.4 ; 0.75$ \\
\hline
\end{tabular}

\begin{tabular}{|c|c|c|c|}
\hline & ${\text { CD } 34^{+}<5 \times 10^{6}(n=125)}$ & CD34 $^{+} \geq 5 \times 10^{6}(n=75)$ & P-value \\
\hline Overall survival (months) & $71(63.6-78.4)$ & $71(38.9-103.1)$ & 0.8 \\
\hline
\end{tabular}

\section{Discussion}

Currently, the standard treatment for MM patients suitable for transplantation is ASCT with high-dose melphalan after induction therapy (1). Though standard, the procedure is still challenged by inevitable relapses threatening long-term remissions (8). Since MM is a relapsing disease, CD34 ${ }^{+}$HPCs are needed for subsequent ASCT. Therefore, excess CD34+ HPCs should be collected in the first stem cell mobilization (9). The relationship of the number of $\mathrm{CD}_{3} 4^{+} \mathrm{HPCs}$ 


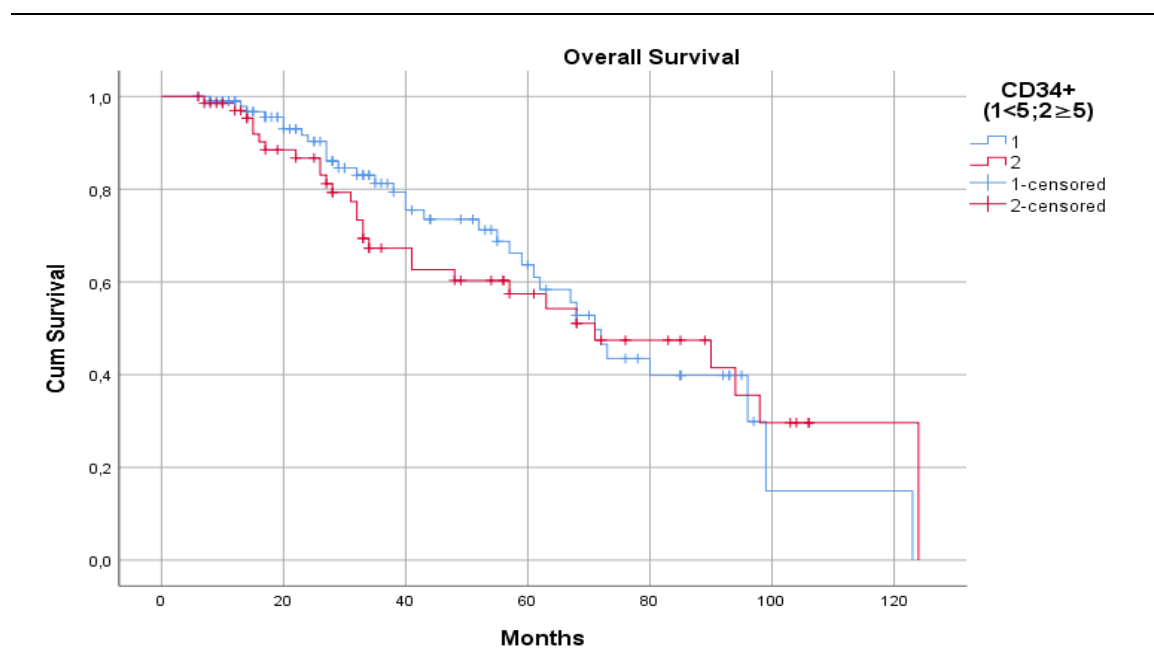

Figure 1. Kaplan-Meier Survival graph showing the difference in OS among patients with the infusion of above and below $5 \times 10^{6}$ cells $/ \mathrm{kg} \mathrm{CD} 34^{+} \mathrm{HPC}(\mathrm{P}=0.8)$

administered in the first stem cell transplant with neutrophil, platelet engraftment, and survival was controversial in the literature (4-6). As a result, stem cell mobilization and ASCT are complex processes involving many procedures and treatment applications. For this reason, our study carried the advantage of a unicenter study with the established staff and a standard conditioning regimen (i.e., melphalan) and standard operating procedures.

In a study, the median os times was demonstrated as 103 months (11-144) and 145 months (123-166) for patients who were administered $<5 \times 10^{6}$ cells $/ \mathrm{kg}$ and $\geq 5 \times 10^{6}$ cells/kg of CD34+ HPCs, respectively ( $\mathrm{P}=0.009)(4)$. Moreover, it was observed that doses of $\mathrm{CD} 34^{+}$cells exceeding $6 \times 10^{6}$ cells $/ \mathrm{kg}$ were associated with faster hematopoietic recovery and improved OS (5, 10 ). In some studies, a high number of re-infused CD34 ${ }^{+}$HPCs was reported to reduce hospitalization by shortening the engraftment time $(11,12)$. Nevertheless, the results of another study showed that a CD34+ HPCs administration of 2.5-5 $\times 10^{6}$ cells/kg or $5 \times 10^{6}$ cells $/ \mathrm{kg}$ did not provide any difference in survival $(\mathrm{P}=0.186)$ (13). In our study, the $\mathrm{CD}^{4} 4^{+}$HPCs dose above $5 \times 10^{6}$ cells $/ \mathrm{kg}$ threshold was demonstrated not to impact the OS positively.

In one study, a negative significant correlation was revealed between the number of re-infused CD34+ HPCs and neutrophil/platelet engraftment times $\quad(r=-0.32, \quad P \leq 0.001 ; \quad r=-0.27, \quad P \leq 0.001$, respectively) (4). In our study, no significant correlation was observed between the neutrophil/platelet engraftment time and the number of $\mathrm{CD}^{+} 4^{+}$HPCs. This discrepancy in the outcomes might be attributed to the number of patients relative to our research with that in the previous study $\left(<5 \times 10^{6}\right.$ cells $/ \mathrm{kg}$ CD $34^{+}$HPCs $62.5 \%$ and $38 \%, \geq 5 \times 10^{6}$ cells $/ \mathrm{kg}$ CD $34^{+}$HPCs $37.5 \%$ and $60 \%$, respectively) (11).

The International Myeloma Working Group states that the aim should be to collect a minimum of $4 \times 10^{6} \mathrm{CD} 34^{+}$cells $/ \mathrm{kg}$. They suggest collecting an average of $8-10 \times 10^{6} \mathrm{CD} 34^{+}$cells $/ \mathrm{kg}$, if possible (9). This is because these goals can allow most patients with myeloma to undergo at least two autografts with an optimal dose of $\mathrm{CD}^{+} 4^{+}$cells during their disease (9). In our study, the administration of $>5$ $\times 10^{6} \mathrm{CD} 34^{+}$cells $/ \mathrm{kg}$ did not affect the platelet and neutrophil engraftment time and OS. Therefore, since MM is a recurrent disease, excess CD34 ${ }^{+}$HPC should be collected in the first stem cell mobilization; however, $2-5 \times 10^{6} \mathrm{CD}^{2} 4^{+}$cells $/ \mathrm{kg}$ should be re-infused; as a result, stem cells will be available for a chance of having second transplantation in case of recurrence.

\section{Conclusion}

Based on the result, stem cell mobilization and ASCT were found complex processes involving many procedures and treatment applications. The greater number of CD34+ $\mathrm{HPCs}$ re-infusion for ASCT after high-dose melphalan chemotherapy in MM patients did not affect platelet and neutrophil engraftment time and OS; therefore, this amount of reinfusion was not required.

\section{Acknowledgments}

None.

\section{Footnotes}

Author's contributions: $\mathrm{HB}, \mathrm{SB}$, and MB performed research; MSD and TNY designed the research study; SB and Dİ analyzed and interpreted the data; 
HB and BUU wrote the paper. JY, NÖ, and MB collected and processed data; MKÇ and FA reviewed the manuscript.

Conflicts of Interest: The authors declare that there is no conflict of interest.

Ethical Approval: Ethical codes and principles of the Helsinki Declaration were followed during the study. Written permission and Ethics Committee's permission (2020-10/852) were obtained from Abdurrahman Yurtaslan Ankara Oncology Training and Research Hospital.

Funding/Support: The authors received no financial support for the research, authorship, and publication of this study from any public or private organization or institute.

Financial Disclosure: None

Informed Consent: Informed consent was waived due to the retrospective nature of the study, no intervention was performed on patients for the research, routine medical care was applied, and anonymous clinical data were used for the analysis.

\section{References}

1. Bird JM, Owen RG, D'Sa S, Snowden JA, Pratt G, Ashcroft J, et al. Guidelines for the diagnosis and management of multiple myeloma 2011. Br J Haematol. 2011;154(1):32-75. doi: 10.1111/j.1365-2141.2011.08573. [PubMed: 21569004].

2. Child JA, Morgan GJ, Davies FE, Owen RG, Bell SE, Hawkins K, et al. Medical research council adult leukaemia working p: high-dose chemotherapy with hematopoietic stem-cell rescue for multiple myeloma. $N$ Engl J Med. 2003; 348(19):1875-83. doi: 10.1056/NEJMoa022340. [PubMed: $12736280]$.

3. Mohty M, Hubel K, Kroger N, Aljurf M, Apperley J, Basak GW, et al. Autologous haematopoietic stem cell mobilisation in multiple myeloma and lymphoma patients: a position statement from the European group for blood and marrow transplantation. Bone Marrow Transplant. 2014;49(7):86572. doi: 10.1038/bmt.2014.39. [PubMed: 24686988].

4. Aladağ Karakulak E, Demiroğlu H, Büyükaşik Y, Turgut $M$, Aksu S, Sayinalp N, et al. CD34+ Hematopoietic progenitor cell dose as a predictor of engraftment and survival in multiple myeloma patients undergoing autologous stem cell transplantation. Turk J Med Sci. 2020;50(8):1851-6. doi: 10.3906/sag-2001-173. [PubMed: 32512672].

5. Stiff PJ, Micallef I, Nademanee AP, Stadtmauer EA, Maziarz RT, Bolwell BJ, et al. Transplanted CD34(+) cell dose is associated with long-term platelet count recovery following autologous peripheral blood stem cell transplant in patients with non-Hodgkin lymphoma or multiple myeloma. Biol Blood Marrow Transplant. 2011;17(8):1146-53. doi: 10.1016/j.bbmt.2010.11.021. [PubMed: 21126595].

6. Giralt S, Costa L, Schriber J, Dipersio J, Maziarz R, McCarty J, et al. Optimizing autologous stem cell mobilization strategies to improve patient outcomes: consensus guidelines and recommendations. Biol Blood Marrow Transplant. 2014; 20(3):295-308. doi: 10.1016/j.bbmt.2013.10.013. [PubMed: 24141007].

7. Yiğenoğlu TN, Başcı S, Ulu BU, Bakırtaş M, Kılınç A, Şahin D, et al. Inferior prognosis in poor mobilizing myeloma patients. Transfus Apher Sci. 2020;59(3):102722. doi: 10.1016/j.transci.2020.102722. [PubMed: 32014363].

8. Nijhof IS, van de Donk NW, Zweegman S, Lokhorst HM Current and new therapeutic strategies for relapsed and refractory multiple myeloma: an update. Drugs. 2018; 78(1):19-37. doi: 10.1007/s40265-017-0841-y. [PubMed: 29188449].

9. Giralt S, Stadtmauer EA, Harousseau JL, Palumbo A Bensinger $\mathrm{W}$, Comenzo RL, et al. International myeloma working group (IMWG) consensus statement and guidelines regarding the current status of stem cell collection and highdose therapy for multiple myeloma and the role of plerixafor (AMD 3100). Leukemia 2009;23(10):1904-12. doi: 10.1038/leu.2009.127. [PubMed: 19554029].

10. Bensinger W, Appelbaum F, Rowley S, Storb R, Sanders J, Lilleby $\mathrm{K}$, et al. Factors that influence collection and engraftment of autologous peripheral-blood stem cells. J Clin Oncol. 1995; 13(10):2547-55. doi: 10.1200/JC0.1995.13.10.2547. [PubMed: 7595706].

11. Lanza F, Campioni DC, Hellmann A, Milone G, Wahlin A, Walewski J, et al. Individual quality assessment of autografting by probability estimation for clinical endpoints: a prospective validation study from the European group for blood and marrow transplantation. Biol Blood Marrow Transplant. 2013; 19(12):1670-6. doi: 10.1016/j.bbmt.2013.08.005. [PubMed: 23988403].

12. Siena S, Schiavo R, Pedrazzoli P, Carlo-Stella C. Therapeutic relevance of $\mathrm{CD} 34$ cell dose in blood cell transplantation for cancer therapy. I Clin Oncol. 2000;18(6):1360-77. doi: 10.1200/JCO.2000.18.6.1360. [PubMed: 10715309].

13. Jillella AP, Ustun C. What is the optimum number of CD34+ peripheral blood stem cells for an autologous transplant? Stem Cells Dev. 2004;13(6):598-606. doi: 10.1089/scd.2004.13.598. [PubMed: 15684827]. 